\title{
Competency Based Approach between Theory and Practice
}

\begin{abstract}
This paper purports to investigate the extent to which preservice middle school teachers of English at the Teachers Training School of Constantine (ENSC) are able to put into practice the Competency based approach (CBA) tenets. A sample population of 42 pre-service middle school teachers took part in the study through a survey which revealed that a gap exists between the theoretical framework of the CBA gained in the school, and the practical implementation of that knowledge. Thus, more efforts should be spent to ensure a better teacher quality and training at the level of the school.

Key terms: Education, Competency Based Approach, Teacher

Training
\end{abstract}

\section{Faiza BADER}

Hacene HAMADA

Teacher Training School (ENS)

Constantine

(Algeria)

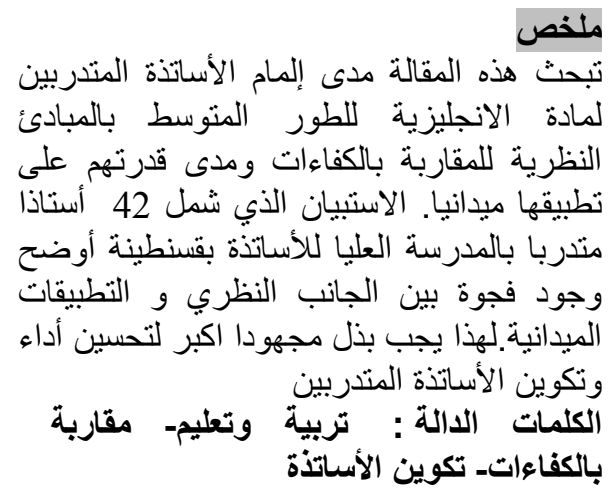

\section{Introduction}

$\mathbf{B}_{\text {y the year 2000, Algeria started a series of }}$ reforms that involved almost all economic, social and educational domain; education was considered as the key towards any kind of political and/or economic growth (Toualbi-Thaalibi, 2006; Tawil, 2006). Still, an increasing necessity to reform the Algerian school was triggered by a new era of globalization and technological progress the world was witnessing, and in this respect the general director of the UNESCO Koichuo Matsuura (2005) states: A reform of the contents and learning methods, as well as a reorganization of the structures of national education are also becoming indispensible so as to permit the adaptation and integration of the Algerian society in a context of an economic globalization and acceleration of technological progress. (p.7). [translated from French] 
As a new teaching methodology needed to be considered so as to cope with the demands of the globalized world, a National Commission of educational reforms was installed in 2000 (Conseil National de la Reforme de l'Education -CNRE), to evaluate the then existing educational system and give over suggestions. As reports revealed weaknesses in 2001, UNESCO agreed in 2003 to budget the Algerian reforms and Algerian officials met and set the Program of Support for the Reform of the Algerian Educational System (Programme d'Appui de l'UNESCO a la reforme du Système Educatif Algérien: PARE). These reforms induced the inception of the Competency Based Approach (CBA) for the academic school year 2003/2004. In 2006, three years after the institution of the CBA, the PARE project and the UNESCO supervised study days organized by the Ministry of National Education (MEN) and conference acts were issued under the title of 'Educational Reform and Pedagogical Innovation in Algeria' (Réforme de l'Education et Innovation Pédagogique en Algérie.)

Those educational reforms were not exempt from criticism and moans grew in dissatisfaction; Bouhadiba (2015), among others, views that this change 'resulted in a sudden shift for the teacher and the learner who were not prepared in a thoughtful and coherent manner' (14).

If the above quotation relates to teachers in general, the following questions are raised in relation to teachers being trained in a specialized school that is the Teachers Training School of Constantine in order to check the future teachers' readiness to apply the CBA:

1. What do pre-service middle school teachers of English know about the CBA?

2. After four years of theoretical teaching courses, and three months of practical training courses in different middle schools in Constantine, are pre-service middle school teachers of English able to put into practice the CBA?

\section{Theoretical Framework of the Competency based Approach}

The competency based approach (CBA) as stated by Richards and Rodgers (2001) adheres to the interactional and functional views of language learning; it advocates the determination of learning goals in terms of measurable and precise descriptions of knowledge, skills and behaviors, expected from the part of learners at the end of a course of study. In like manner, Bowden (2004) asserts that determining outcomes in explicit and precise ways are prerequisites for a successful career. Emphasis on observable behaviors goes back to the origins of CBA which, as stated by Tuxworth (1990), drew on industrial and business models that specified outcomes in terms of behavioral objectives. Similarly, Richards (2006) views that work related and survival oriented language teaching relied widely on the competency-based model, so as to teach students the basic skills they need for every day survival situations. For Docking (1994), a CBA is:

(...). organized not around the notion of subject knowledge but around the notion of competency. The focus moves from what students know about language to what they can do with it. The focus on competencies or learning outcomes underpins the curriculum framework and syllabus specification, teaching strategies, assessment and reporting. (p.16) 
Accordingly, CBA is stressing what learners can do with language not what they know about language. The curriculum, the syllabus, the teaching strategies and assessment tools are organized around competency development rather than language knowledge. Within this scope, Aurebach (1986) lists eight key features of the CBA

1. A focus on successful functioning in society: The goal is to enable students to become autonomous individuals capable of coping with the demands of the world.

2. A focus on life skills: Rather than teaching language in isolation, CBA/ESL teaches language as a function of communication about concrete tasks. Students are taught just those skills required by the situations in which they will function.

3. Task-or performance-centered orientation: What counts is what students can do as a result of instruction. The emphasis is on overt behaviors rather than on knowledge or the ability to talk about language and skills.

4. Modularized instruction: Objectives are broken into narrowly focused sub objectives so that both teachers and students can get a clear sense of progress.

5. Outcomes which are made explicit a priori: Outcomes are public knowledge, known and agreed upon by both learner and teacher. They are specified in terms of behavioral objectives so that students know exactly what behaviors are expected of them.

6. Continuous and ongoing assessment: Students are pretested to determine what skills they lack and post tested after instruction in that skill. If they do not achieve the desired level of mastery, they continue to work on the objective and are retested. Program evaluation is based on test results and, as such, is considered objectively quantifiable.

7. Demonstrated mastery of performance objectives: Rather than the traditional paper- -and- pencil tests, assessment is based on the ability to demonstrate prespecified behaviors.

8. Individualized, student-centered instruction: In context, level, and pace, objectives are defined in terms of individual needs; prior learning and achievement are taken into account in developing curricula. Instruction is not time-based; students progress at their own rates and concentrate on just those areas in which they lack competence (414-415).

Weddel (2006) resumes the different stages of CBA pedagogy into; first, an assessment of the learners needs, second a selection of the competencies that should be specific and stated in measurable behaviors. Third, determination of the target instruction; the content is based on learners goals i.e. competencies. Last but not least evaluation of the competency, learners continue to learn until mastery of the competency. Assessment should be criterion-referenced: each competency must have clear performance criteria, and learners need to be assessed on how successful they are in performing tasks, not how well they know about language.

\section{Definition of Competency}

Some dichotomies are made between competency and competence, competency for Bowden (2004) is a diminutive of competence. Competence, for some, is job related, and determines an individual's capacity to meet the requirements of a job. Competency, on the other hand is person related because it is all about a human's 
knowledge, skills, and abilities integrated to effectively in life or workplace. Competency will be retained as it pertains to contexts, life or work places.

The Competency based approach (CBA) as an educational movement is, then, having competencies as its organizing principle. Competencies are - according to the Report of the National Postsecondary Education Cooperative Working Group on Competency-based Initiatives in Post Secondary Education (NPEC Report, Jones, and Voorhees, 2002):

(...) the result of integrative learning experiences in which skills, abilities, and knowledge interact to form bundles that have currency in relation to tasks for which they are assembled and demonstrations are the result of applying competencies. It is at this level that performance can be assessed. (P.7)

Competency is then an integration of knowledge, skills, and abilities that lead to demonstrable and measurable behaviors as a manifestation of this competency. Still, Mrowicki (1986) considers competencies as the description of knowledge, skills, attitudes and behaviors necessary to the performance of a real life task. Well designed Competencies, according to Griffith and Lim (2014), need first, to describe specific knowledge and skills that can be applied in new and complex contexts. Second, clear performance criteria must be described; standards need to be clear. Third, each competency must be personalized.

Examples of competencies listed by Mrowicki (ibid) can involve the following:

Topic: shopping

1. Read a limited number of basic signs.

2. Ask about the price of items.

3. Express basic food needs.

4. Request correct change when incorrect change is received.

5. Express intention to buy the item.

6. Read abbreviations for common measures and weights.

7. State clothing needs, including size and color.

8. Differentiate sizes by reading tags and tape measure

\section{Role of Teachers}

Teachers under a learner-centered approach, that is the CBA, are no more the detainers of knowledge, but facilitators and guides; they assist their learners all along the path towards competency acquisition. Still, they have to determine what and how well learners must perform; they give clear instructions and make sure that every learner understands the task. In this respect, Paul (2008) maintains that teachers need to be providers of authentic materials, activities, and practice opportunities. Those materials, as advanced by Griffith and Lim (2014), need to be oriented toward doing rather than knowing, and related to any domain of life. Typical areas, for which competency-based activities can be suggested, can involve job interview or job application; These areas are described by Docking (1994) '..... as a collection of units of competencies' which consist of 'specific knowledge, thinking processes, attitudes, and perceptual and physical skills' (14); the competency specified needs to be dissected 
into sub skills that call upon a specific knowledge, skills and attitudes. Teachers need to guarantee an individualized instruction, as learners are supposed to move at their own paces; instruction is not time-based. They are also required to provide constructive feedback on how well learners are doing toward successful completion of tasks; they have to ensure an ongoing assessment.

\section{Role of the learner}

The learner is active and learns to learn by acting upon his learning; he is at the heart of this instruction. Richards and Rodgers (2001) advance that the learner needs to practice and perform the skills taught; he has to do something with the language, not just knowing about the language. He is required to be well aware of the appropriate and purposeful uses of the targeted competencies. Moreover, he must be able to transfer the knowledge gained in school to pertinent contexts of use outside, in real life. Mastery of the stated competency determines the learner's success. If the specified competency is unattained he stays in the actual program.

\section{Evaluation under the CBA}

Evaluation under the CBA needs to be performance based. It is of two types, formative or summative. The formative is ongoing and continuously used all along the route toward the prescribed competency. Summative assessment, on the other hand, determines competency mastery; it is administered as a final test. Failure in summative tests equals retaking the same module and not moving on to the next competency. The summative assessment, as stated by Griffith and Lim (2014), needs to involve performance based tests not fill -in- the-blank, and multiple choice tests. Docking (1994) shares the same stand when he says that "instead of norm-referencing assessment, criterion-based assessment procedures are used in which learners are assessed according to how well they can perform on specific tasks." (16). Assessment under the CBA needs to consider not what they know, but how far they can meet the standards of the specific tasks. Assessment under the CBA is criterion-referenced instead of norm-referenced.

\section{Competency Based Language Teaching in Algeria}

The competency based instruction extended to language teaching is dubbed Competency based Language Teaching or CBLT. CBLT in Algeria targets three competencies as stated in the Official Accompanying Documents of $2^{\text {nd }}$ year Middle School (2003); to interact orally, to interpret, and to produce authentic oral and written messages. So as to achieve those competences, learners are placed in front of problem situations that stimulate their cognitive abilities and whose resolution requires the integration of knowledge, skills and attitudes.

The socio-constructivist view of learning, advocated here, is promoted through project work which is the pillar of CBA, as stated in the official documents. In a group work, learners throughout a real life task performance display the targeted competencies. Assessment is also criterion-referenced. 


\section{Research Methodology}

\section{Participants}

In this study, all the participants were all fourth year middle school pre-service teachers of English at the Teachers Training School of Constantine. A total of 42 preservice teachers were purposefully sampled because they were in their final year of studies; hence, they were supposed to have developed the ability to put into practice CBA, on score of that, in just few months they will graduate and start teaching. The study took place in March 2016, and by September 2016 they would start teaching. Moreover, the sample had attended a three months practical training, including a Full Time or a Block Training exceptionally extended, this school year 2015/2016, to one month, instead of 15 days. This practical training presented the trainees or pre-service teachers with an opportunity to practice the learnt knowledge about CBA.

\section{Research tool}

To help address a large number of subjects i.e. the whole promotion of pre-service middle school teachers at the Teachers Training School of Constantine, ENSC, a questionnaire was used (see Appendix). It consisted of an 18 item-questionnaire divided into two sections; one theoretical (items from 1 to 13) and the other practical (items from 14 to 18). All 42 pre-service middle school teachers at the Teachers Training School of Constantine participated in the study. One day after the end of the Block Training i.e. the $7^{\text {th }}$ March, 2016 pre-service middle school teachers, in the presence of the researcher, were asked to fill it up, and had one hour to do so.

\section{Findings of the study}

The results of the study are categorized into theoretical content and practical applications about the CBA, according to the organization of the questionnaire.

\section{Theoretical considerations}

\section{Language is communicative}

The study findings revealed that $83 \%$ of pre-service middle teachers of English at the Teachers School of Constantine believe that CBA is communicative, because it seeks to enable learners communicate and interact, it is not based on the structural view of language whereby language acquisition equals mastery of the structure of language. But $17 \%$ of our sample considered CBA as an approach putting emphasis solely on form, no communication is sought after (See figure1 below).

\section{CBA relies on observable performance}

$86 \%$ of the sample population reported that CBA relies on observable performances as indicators of competency acquisition, against $14 \%$ who answered that CBA does not rely on observable behaviors because, according to them, it is about what learners know about language, not what they can do with language. (See figure 1). 


\section{Definition of competency}

$90 \%$ of the pre-service middle school teachers provided the correct definition for competency which is the integration of knowledge, skills and attitudes for the performance of a real life task. $10 \%$, however, could not provide a correct definition of competency. (See figure1).

\section{Project work is important}

93\% of our sample considered project work under the CBA as really important, because it is a real life task that allows the manifestation of the competencies advocated by the approach in the Algerian school. The 7\% left viewed project work as unimportant under the CBA. (See figure1).

\section{Assessment under the CBA is criterion- referenced}

$64 \%$ of our pre-service teachers answered that each competency needed to have clear performance criteria, against $36 \%$ who stated that competencies did not need to have clear performance criteria.

At the theoretical level, pre-service middle school teachers did display a good mastery of the main features that characterize the CBA. In some questions the explanations they used to justify their choices, were not a hit or miss matter, but were rather carefully selected.

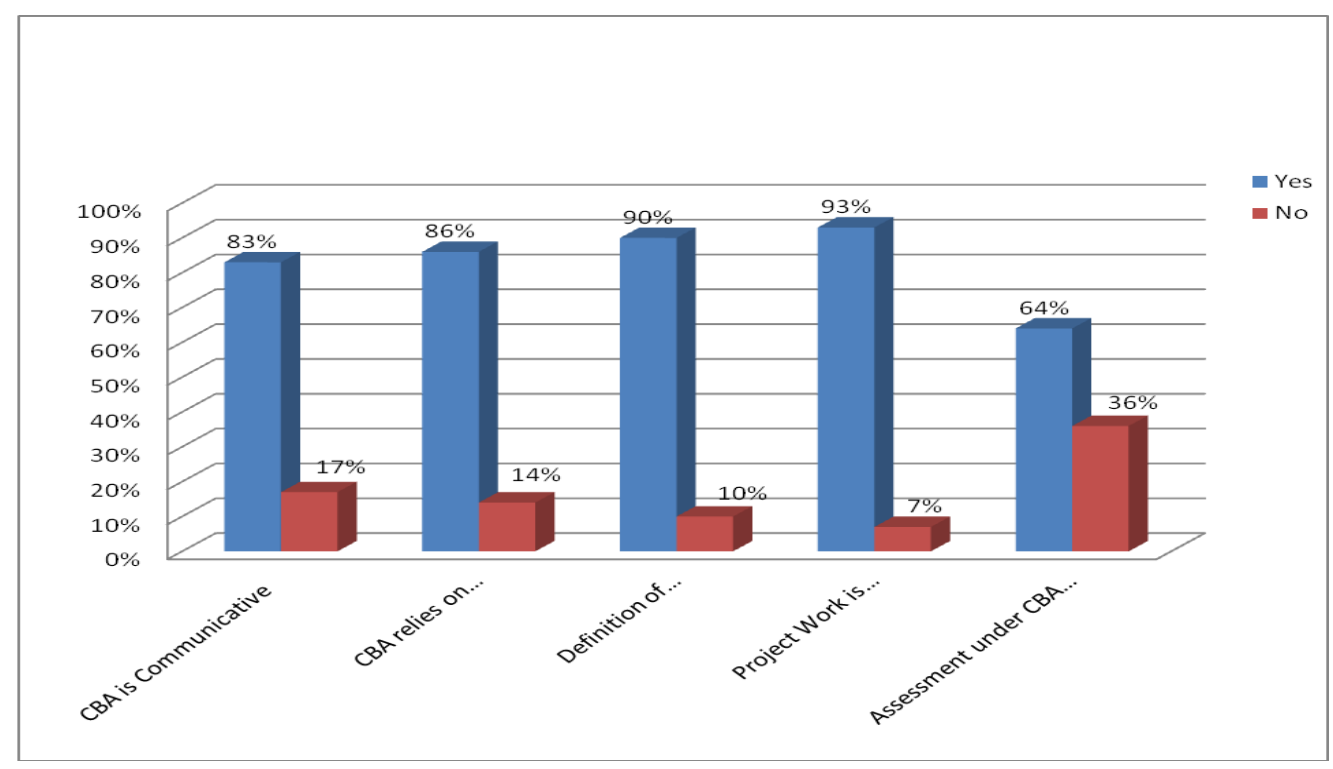

Figure 1: CBA Theoretical Considerations of Pre-service Middle Scholl Teachers 


\section{Practical considerations}

\section{Competency statement}

When asked to translate the theoretical definition of competency into a concrete example, just $4 \%$ of the pre-middle school teachers of English succeeded in doing so, and gave as examples, 'to scan a train schedule for specific information', and 'to give a food recipe'. $96 \%$, a considerable number of our participants, proved unable to express it in terms of a real life task that displays an observable behavior; they restricted it to activities aiming at the mastery of the linguistic components of language, mainly grammar. According to them, CBA seems to focus on what learners know about language rather than what they can do with Language. (See figure2, below).

\section{Three sub-skills leading to the stated competency}

Figure 2 below displays that $96 \%$ of our population resumed the sub-skills to listening, speaking, reading or writing. The unspecified competency did not help them decide about which sub-skills to select. Only the $4 \%$ managed to suggest adequate subobjectives such as 'learners are expected to be able to use the imperative', 'to name food utensils', or 'to name the ingredients of a food recipe', 'to look for someone's number in a telephone directory', 'to read a map, or 'departure time in a train station'. (See figure 2).

\section{Teacher's roles}

The teacher's roles for the $96 \%$ participants were restricted to what they know in theory about the roles teachers need to perform in a learner-centered approach the case of CBA; the teacher, for them, is a facilitator, a guide or a motivator. In fact the subskills they stated gave way to a teacher-fronted classroom, where the teacher controls not facilitates the learning process; they expressed the roles in terms of 'the teacher explains, corrects, presents....". The 4\% left suggested a guide, and a facilitator still, but expressed the sub-skills in terms of what learners are expected to do, not what teachers are supposed to do. (See figure 2.)

\section{Pupils' roles}

The majority did not manage to explain how pupils can move toward competence acquisition, they formulated the roles in terms of "to follow carefully the teacher', or ''to answer questions asked by the teacher'. The $4 \%$ explained, however, that pupils needed to act upon their learning; they were not passive. (See figure 2).

\section{Assessment plan related to the stated competency}

Since the competency stated by the majority did not display a specific observable behavior, no specific criteria could be set for its assessment. The tasks suggested were in their majority real life ones, but were not relevant. Those participants who succeeded in stating adequate real life tasks for both 'a food recipe', and 'scanning a train schedule', suggested for the former preparing a dish in front of the whole classmates after giving the different ingredients in English, and the names of the 
utensils used had to be named as well; or 'bringing a bus timetable' for the latter, and 'asking classmates for a specific destination'.

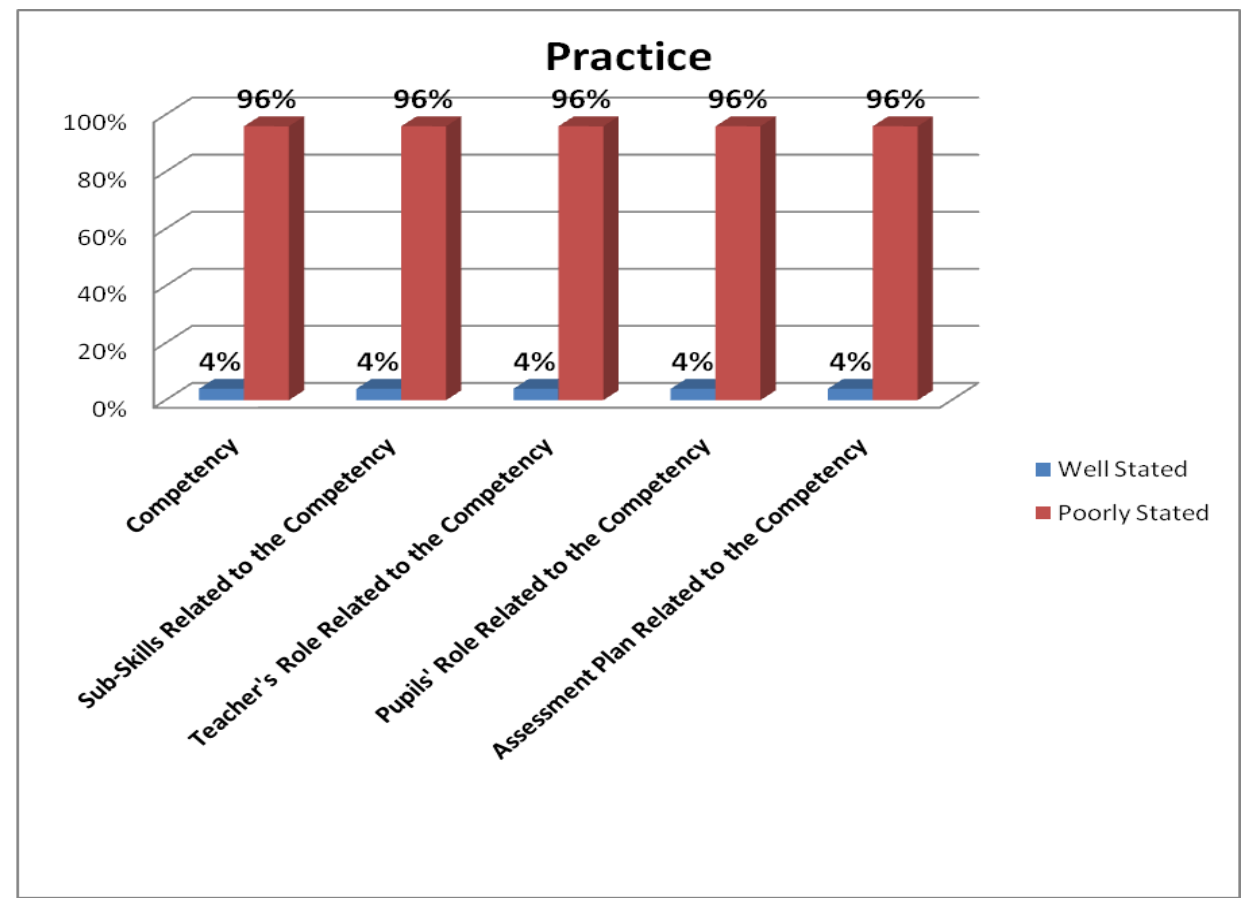

Figure Two: CBA Practical Considerations of Pre-service Middle School

\section{Discussion}

The results in this study came to prove that a considerable number of pre-service middle school teachers at the Teachers Training School of Constantine do theoretically know about the CBA, but are unable to transfer this knowledge into a practical context of use. They know that CBA adheres to the interactional and functional theories of language learning, and that language is used as a tool for communicative purposes. CBA for the majority of the participants builds on what learners can do with language, not what they know about language. Competency is for nearly all the sample an integration of knowledge, skills, and attitudes that require clear performance criteria. Learners, for them, need to transfer their knowledge to new contexts of use, and have to react to problem situations, if they are to make their learning sustainable and viable. Project work is the most important part in the textbooks because, according to them, it is the context where competencies manifest themselves.

The theoretical section results were disapproved by the practical section findings; just $4 \%$ of our pre-service middle school teachers were able to suggest a competency 
that involved a task likely to be encountered in real life; scanning a train schedule for specific information, and giving a food recipe.

The remaining majority could not express competency in terms of a real performance that bears to a real life task. Project work was substituted for competency; it is for them the outcome itself, not the tool. Then, this project turned to be viewed as the context where the competencies manifest themselves. Such projects are normally tasks that help develop competencies; they are not the competency per se.

Three reasons behind this breach or gap between theory and practice can be traced to the training school, the mentors, or the pre-service teachers themselves. Even if thorough theoretical courses are dispensed at the level of the school, saying is one thing and doing is another thing; what trainees know about the CBA cannot guarantee that they can put it into practice. Consequently, the training school should provide more practical training opportunities; three months are not enough to help the trainees or preservice teachers put into practice their theoretical background. Furthermore, some tutors, supposed to guide the trainees, do not know how to put into practice the CBA. Lack of those tutors' training in using CBA can be behind pre-service teachers' inability to practice CBA. Teachers at the Teachers Training School have to reconsider their courses and assessment tools, if they expect their pre-service teachers to bridge the gap between theory and practice.

\section{Conclusion}

The study sheds light on the extent to which pre-service middle school teachers of English at the Teachers Training school of Constantine know about CBA, and how far they are able to put what they know into practice. The conclusion we can draw is that the theoretical courses helped those pre-service middle school teachers of English display an ability to define key features and characteristics related to CBA. However, when asked to translate this theory into practice, they proved unable to do so.

Educational reforms in Algeria will remain hot air if teachers' behaviors do not fuse theory about CBA with practice. The heart and tool of whatever reform in education is, and will remain the teacher, because unless teachers alter or adjust their practices to those changes, the best approach on earth will not work.

\section{References}

[1] Auerbach,E.R.(1986). Competency-based ESL: One step forward or two steps back? TESOL Quarterly, 20(3), 411-429.

[2] Bouhadiba,F.(2015). The Implementation of CBLT in Algeria: from Euphoria to Bitter Criticism. Arab World English Journal, 3-16

[3] Bowden,J.A.(2004). Competency-based education: Neither panacea nor pariah http://cm.htc.ac.ac/events/archive/tend/018 bowden.html

[4] Docking,R.(1994).Competency-based curricula- The big picture.Prospect,9(2),817. 
[5] Documents d'Accompagnement des Programmes de la 2eme Annee Moyenne (2003). Algiers ONEFD.

[6] Griffith and Lim. Introduction to Competency-Based Language Teaching. Mextesol journal 38(2), 1-8.

[7] Jones, and Voorhees.(2002). Report of the National Postsecondary Education Cooperative Working Group on Competency-Based Initiatives in Post Secondary Education (NPEC Report).

[8] Matsuura,k.(2005).Preface. In : La Refonte de la pedagogie en Algerie: Defis et enjeux d'une societe en mutation.Programmes d'appui de l'UNESCO a la reforme du système educatif(PARE), Ministery of education, ed. Casbah and ONPS. pp.7-9.

[9] Mrowicki,L.(1986). Project Work Competency-Based Curriculum. "Approaches and Methods in Language Teaching'. Portland, OR: Northwest Educational Cooperative.

[10] Paul, G.(2008). Competency-Based Language Teaching Report.

Http://glendapaul62.blogspot.com./2008/12/competency-based-teaching.html

[11] Richards,J.C.(2006). Communicative Language Teaching. Cambridge: Cambridge University Press.

[12] Richards,J.C. and T.S.Rodgers.(2001).Approaches and Methods in Language Teaching. Cambridge: Cambridge University Press.

[13] Tawil,S. (2006). Le defi de la qualite de 1 education en Algerie : La qualite et la pertinence de 1 education-un defi mondial. In Ministry of Education. (2006).Reforme de 1 education et innovation pedagogique en Algerie. Programme $d$ appui de 1 UNESCO a la reforme du système educatif PARE.

[14] Toualbi-Thaalibi,N.(2006). Trois annees de reforme de la pedagogie en Algerie : Bilan et perspectives. In Ministry of Education. Reforme de 1 education et innovation pedagogique en Algerie. Programme d appui de 1 UNESCO a la reforme du système educatif PARE.

[15] Tuxworth, E. (1990). Competence Based Education and Training. Competency Based Education and Training. Ed. J. W. Burke. London: Routledge and Francis Group.

[16] Weddel, K.S.(2006). Competency-Based Education and Content Standards. Northern Colorado Literacy Resource Center. 


\section{Appendix}

This questionnaire is part of a research work aiming at investigating the extent to which you, the future middle school teachers of English, know about the competencybased approach, and can put it into practice.

You are kindly requested to tick the appropriate answer, or give full answers where necessary.

Thank you

\section{Theoretical Considerations}

1 The competency-based approach adheres to the structural view of language.

Yes

No

2 If not

3 The competency based approach(CBA) focuses on what learners know about the language, not what they can do with language.

Yes No

4 If not explain

5 The competency based approach is rooted in the behaviourist view of learning

Yes No

6 If not explain

7 Focus in CBA is on outcomes as observable behaviours

Yes

No

8 A competency is

9 Pupils are asked to transfer their knowledge to new contexts of use

Yes

No

10 Pupils are expected to face problem situations inside the class, likely to be encountered in real life

$$
\text { Yes No }
$$

11 Project work in middle school textbooks is presented last because it is the least important part in a file

$$
\text { Yes No }
$$


12 If not explain

13 Each competency does not need to have clear performance criteria

$$
\text { Yes }
$$

No

\section{Practical Considerations}

14 Suggest a competency

15 Name three sub-skills that can help achieve the aforementioned competency

16 State three roles the teacher needs to play in the context of the stated competency

17 Give three roles the pupils need to play

18 Suggest an assessment plan for the above stated competency 